\title{
Runoff data series prediction based on Complete Ensemble Empirical Mode Decomposition with Adaptive Noise and Radial Basis Function Neural Network extension
}

\author{
Jinping Zhang ${ }^{1}$, Youlai Jin $^{1}$, and Honglin Xiao ${ }^{1}$ \\ ${ }^{1}$ Zhengzhou University
}

February 13, 2021

\begin{abstract}
This study investigated the influence of data extension on the decomposition and prediction accuracy of runoff data series. To this end, an original data series was constructed using annual runoff data from a hydrological station in China (Tang Naihai) for the period 1956-2013, and radial basis function neural network (RBFNN) extension was applied to the original data series. Complete ensemble empirical mode decomposition with adaptive noise (CEEMDAN) was then applied to both data series, and their decomposition and prediction results were compared. The decomposition results indicate that the end effect significantly lowers the accuracy of low-middle frequency components. Nevertheless, the end effect could be effectively suppressed and decomposition error could be reduced by applying RBFNN extension. At the end points, the extension data series could more accurately reflect the real fluctuation characteristics of components and subsequent variation trends. Regarding component prediction, the prediction results followed the variation trend of the components themselves, with a rather large gap in the prediction results of low-frequency components between the two groups of data series. The final prediction results obtained from the reconstruction of the component prediction results suggest that the extension sequence has a clearly superior prediction accuracy than the original data series. Hence, when using the CEEMDAN method to process non-stationary hydrological data, multi-time-scale information of the data series can be obtained through reasonable extension after decomposition of the original data series. The acquired information provides evidence for the analysis and prediction of the evolution law of hydrological elements.
\end{abstract}

Runoff data series prediction based on Complete Ensemble Empirical Mode Decomposition with Adaptive Noise and Radial Basis Function Neural Network extension

Jinping Zhang a, b

Youlai Jin a, *

Honglin Xiao a

a: School of Water Conservancy Engineering, Zhengzhou University, Zhengzhou 450001, China

b: Yellow River Institute for Ecological Protection \& Regional Coordinated Development, Zhengzhou University, Zhengzhou, 450001, China

*Corresponding Author: Youlai Jin. E-mail:2735723421@qq.com

Acknowledgements: This research is supported by the National Key R\&D Program of China (Grant No. 2018YFC0406501), Outstanding Young Talent Research Fund of Zhengzhou University (Grant No. 1521323002), Program for Innovative Talents (in Science and Technology) at University of Henan Province (Grant No. 18HASTIT014), State Key Laboratory of Hydraulic Engineering Simulation and Safety, Tianjin 
University (Grant No. HESS-1717) and Foundation for University Youth Key Teacher of Henan Province (Grant No. 2017GGJS006).

\section{Hosted file}

manuscript.pdf available at https://authorea.com/users/287008/articles/508680-runoff-dataseries-prediction-based-on-complete-ensemble-empirical-mode-decomposition-with-adaptivenoise-and-radial-basis-function-neural-network-extension
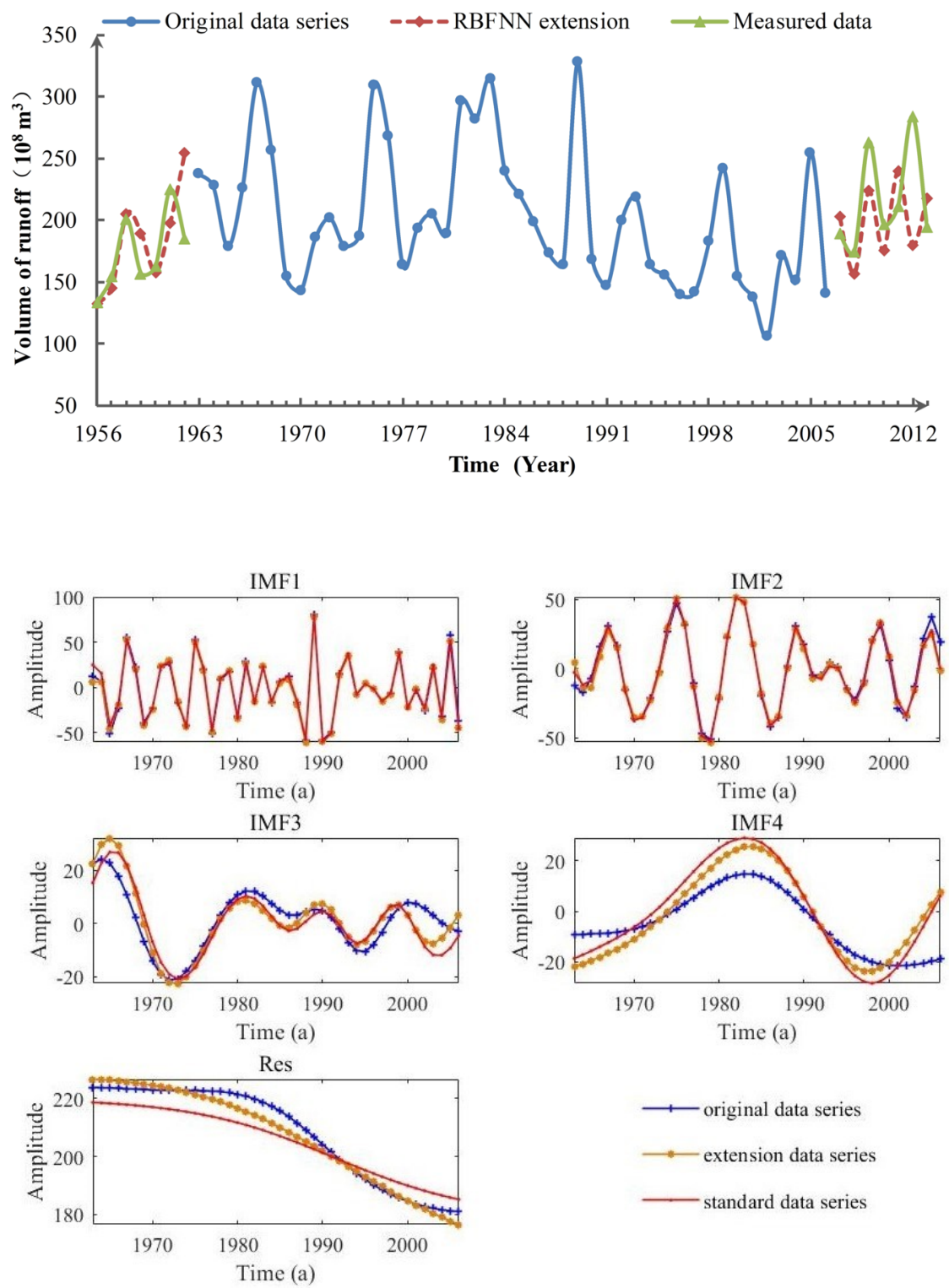

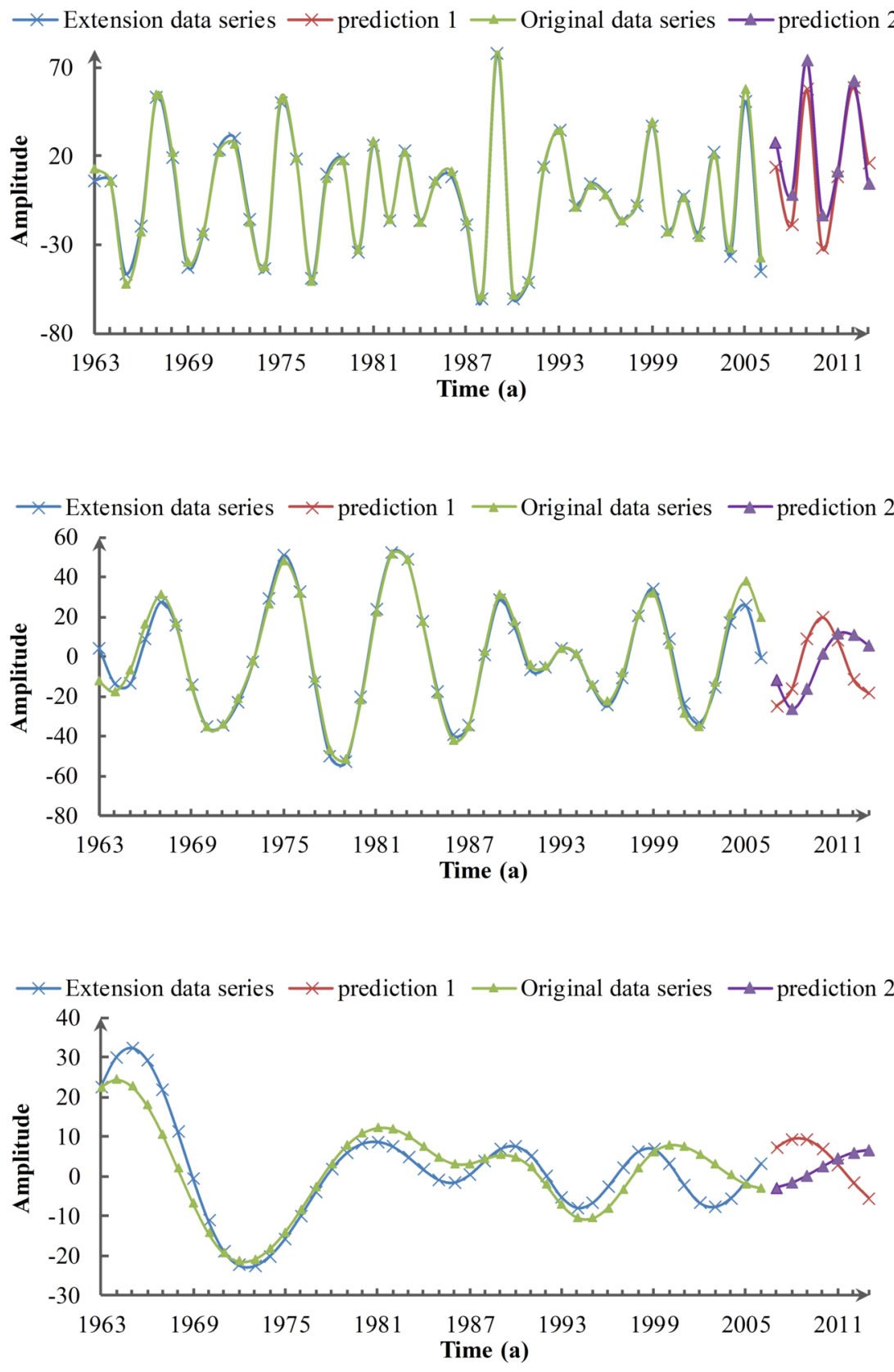

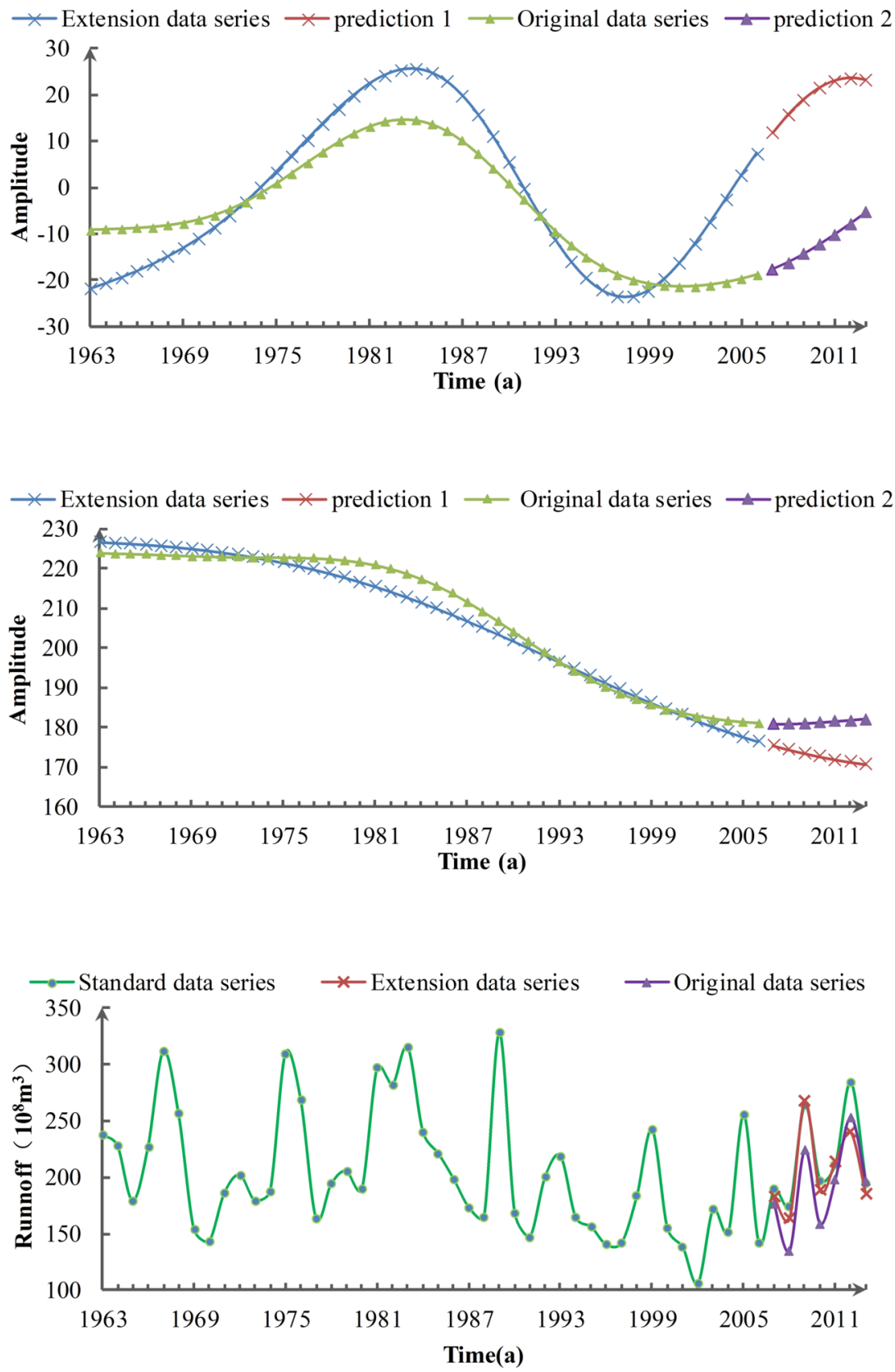

\section{Hosted file}

Table 1. RBFNN extension error.xlsx available at https://authorea.com/users/287008/ articles/508680-runoff-data-series-prediction-based-on-complete-ensemble-empirical-modedecomposition-with-adaptive-noise-and-radial-basis-function-neural-network-extension

\section{Hosted file}

Table 2. Errors in the original data series and extension data series.xlsx available at https: //authorea.com/users/287008/articles/508680-runoff-data-series-prediction-based- 
on-complete-ensemble-empirical-mode-decomposition-with-adaptive-noise-and-radial-basisfunction-neural-network-extension

\section{Hosted file}

Table 3. Prediction results and relative errors.xlsx available at https://authorea.com/ users/287008/articles/508680-runoff-data-series-prediction-based-on-complete-ensembleempirical-mode-decomposition-with-adaptive-noise-and-radial-basis-function-neuralnetwork-extension 